\title{
PENGEMBANGAN MEDIA INTERAKTIF POWERPOINT BERBASIS MODEL DISCOVERY LEARNING PADA MUATAN IPA KELAS IV SD
}

\author{
Fatematus Zahra ${ }^{1}$, Endang Wahyudiana ${ }^{2}$, Waluyo Hadi ${ }^{3}$ \\ ${ }^{123}$ Fakultas Ilmu Pendidikan, Universitas Negeri Jakarta \\ e-mail: fatequery@gmail.com
}

\section{ABSTRAK}

Penelitian ini merupakan penelitian pengembangan (research and development) yang bertujuan untuk menghasilkan produk berupa media interaktif Powerpoint berbasis model Discovery learning untuk siswa kelas IV SD sehingga produk layak digunakan pada saat proses pembelajaran. Model pengembangan menggunakan model Borg and Gall namun hanya sampai pada tahap uji coba produk. Instrumen pengumpulan data berupa wawancara kepada guru dan siswa, angket uji validasi kepada para ahli, dan angket uji coba produk. Berdasarkan hasil validasi ahli media, produk mendapat skor 4,1 dengan kategori baik. Ahli materi sebesar 4,6 dengan kategori sangat baik, dan ahli bahasa mendapat hasil akhir 4,8 dengan kategori sangat baik. Hasil uji coba produk secara perorangan mendapat skor 4,5 dengan kategori sangat baik dan uji coba dalam kelompok kecil mendapat skor 4,6 dengan kategori sangat baik. Berdasarkan hasil penilaian di atas maka dapat dismpulkan bahwa media interaktif powerpoint layak untuk digunakan pada saat pembelajaran IPA khususnya materi upaya pelestarian sumber daya alam untuk siswa kelas IV Sekolah Dasar.

Kata Kunci: Media Powerpoint, Discovery learning, IPA, Pengembangan

\section{ABSTRACT}

The research including development research (Rresearch and Ddevelopment) aims to create a product of the interactive PowerPoint based on model discovery learning for 4th grade student perhaps the product will be useful during the learning process at classroom. The development model used Borg and gall model but only up on-stage product trials. Collection instruments include interviews to teachers and students, the form of a questionnaire sheet to experts and a questionnaire sheet product trial. Based on the validation of media experts, the product get scores 4.1 in good category. Matter expert get 4.6 which is good category and the linguist expert get 4.8 by excellent category. The results of trials one to one were scored 4.5 in a very good category and the trials in small groups scored 4.6 in an excellent category. Based on the results, then can be concluded that interactive PowerPoint media with a combination of discovery models is feasible to be used in the science learning process, especially materials of natural resources conservation for 4th grade student.

Keywords: Powerpoint Media, Discovery Learning, Science, Development. 


\section{PENDAHULUAN}

Perkembangan teknologi yang semakin pesat turut berdampak pada seluruh bidang kehidupan. Salah satunya dalam bidang pendidikan, pemanfaatan teknologi dalam kegiatan belajar akan berdampak pada peningkatan kualitas pembelajaran.

Sebagai penanggung jawab keberhasilan proses pembelajaran di kelas, guru dituntut untuk mampu menggunakan media pembelajaran dan model pembelajaran yang tepat agar proses pembelajaran dapat berjalan secara efektif dan efisien. Media yang digunakan dalam suatu model pembelajaran dapat mempermudah pelaksanaan dari model itu sendiri dalam proses pembelajaran (Astuti et al., 2019). Penelitian dengan mengkombinasikan media dan model pembelajaran ini juga telah dibuktikan oleh (Jalil, 2016), (Ernawati, 2017), (Kusrini, 2018), dan (Astuti et al., 2019).

Media pembelajaran penting sekali karena dapat mempermudah proses komunikasi antara guru dengan siswa. Media pembelajaran menurut (Arsyad 2017:4) adalah segala bentuk dan saluran yang digunakan untuk menyampaikan pesan atau informasi yang mengandung maksud-maksud pengajaran. Guru sebagai fasilitator harus mempertimbangkan media apa yang akan dipilih agar materi yang akan disampaikan dapat dipahami dengan mudah oleh siswa karena penggunaan media dapat merangsang pikiran, perasaan, perhatian dan kemauan siswa untuk belajar (Nunuk Suryani 2010:5)

Salah satu pelajaran yang diajarkan di tingkat sekolah dasar adalah Ilmu Pengetahuan Alam (IPA). IPA adalah proses mempelajari alam semesta dengan pengamatan dan prosedur ilmiah sehingga mendapatkan kesimpulan (Rahayu, 2018). Oleh karena itu, IPA merupakan wadah untuk mengasah rasa ingin tahu siswa terhadap alam semesta dan lingkungan sekitar dan melatih siswa untuk memecahkan masalah yang mereka hadapi dengan menggunakan metode ilmiah.

Hasil observasi yang peneliti temukan di SDN 03 Lenteng Agung, permasalahan yang timbul akibat sistem pembelajaran jarak jauh (PJJ) khususnya dalam pembelajaran IPA antara lain: penggunaan media pembelajaran yang masih minim dan kurang variatif sehingga siswa cenderung pasif selama proses pembelajaran, proses pembelajaran yang sangat berpusat pada guru karena siswa lebih sering diberikan tugas dan kurang adanya interaksi guru dengan siswa. Selain itu, karena keterbatasan alat peraga hal ini meneyebabkan guru mengalami kesulitan dalam memvisualisasikan materi tertentu yang sifatnya abstrak. Siswa juga tidak bisa lagi praktik secara bersama-sama seperti yang biasanya dilakukan sebelum adanya covid-19. Berdasarkan permasalahan tersebut peneliti mencoba memberikan solusi alternatif dengan melakukan pengembangan berupa media interaktif powerpoint berbasis model discovery learning pada muatan IPA.

Microsoft Powerpoint adalah suatu program presentasi untuk menyampaikan atau menjelaskan ide, laporan atau informasi kepada siswa secara audio visual (Astuti et al., 2019) Penggunaan Powerpoint membuat pembelajaran jadi semakin menarik karena mengombinasikan beragam kemampuan pengolahan teks, gambar, warna dan animasianimasi yang dapat dengan mudah diolah sehingga dapat memberikan gambaran nyata terhadap materi yang akan di pelajari (Dariyanto 2016:181). Selain itu microsoft powerpoint dapat dijadikan bahan ajar yang bersifat dua arah (interaktif) dimana siswa tidak hanya sebagai pendengar atau penonton saja namun juga siswa terlibat aktif dalam proses pembelajaran (Azura et al., 2019). 
Menurut (Muhammad Kadri, 2015) discovery learning adalah model pembelajaran dengan pendekatan konstruktivisme. Melalui model ini guru hanya berperan sebagai fasilitator, siswa diajak untuk menemukan sendiri apa yang sedang ia pelajari kemudian mengkonstruksi pengetahuan itu dengan memahami maknanya (Kristin, 2016). Penerepan model discovery learning dalam pembelajran IPA memliki beberapa kelebihan diantaranya dapat membangkitkan rasa ingin tahu siswa, melatih siswa dalam memecahkan masalah dengan sikap ilmiah, dan meningkatkan rasa percaya diri siswa (I Made Putrayasa, H. Syahruddin, 2014)

Hasil penelitian sebelumnya yang dilakukan oleh (Kusrini, 2018) menunjukkan bahwa model discovery learning dengan bantuan Powerpoint dapat meningkatkan hasil belajar siswa pada kelas X IPA 3 di SMA Negeri 2 Palu. Selanjutnya, penelitian yang dilakukan oleh (Astuti et al., 2019) Media powerpoint yang dikembangkan dan dikombinasi dengan model discovery learning menunjukkan layak untuk digunakan karena model discovery learning dapat mendorong rasa ingin tahu siswa, melatih siswa untuk mengonstruksi pengetahuan mereka secara mandiri dan penggunaan media interaktif powerpoint ini membuat pembelajaran menjadi lebih terarah dan membuat suasana belajar menjadi menyenangkan karena dilengkapi dengan suara, video, gambar, dan animasi. (Ernawati, 2017) juga membuktikan dalam temuannya bahwa terdapat pengaruh yang positif terhadap penerapan model pembelajaran discovery learning dan penggunaan powerpoint terhadap prestasi belajar siswa.

Berdasarkan alternatif solusi yang peneliti ajukan, maka diperlukan penilaian kelayakan agar media interaktif powerpoint berbasis model discovery learning ini bisa digunakan dalam proses pembelajaran. Maksud dari media interaktif powerpoint berbasis model discovery learning adalah sebuah media yang menggunakan software powerpoint untuk menyampaikan materi pembelajaran sekaligus memasukkan model discovery learning didalamnya yang bertujuan untuk memudahkan proses kegiatan belajar mengajar sehingga menghasilkan pembelajaran yang efektif. Tujuan penelitian ini adalah untuk mengetahui kelayakan dari media interaktif powerpoint berbasis model discovery learning pada muatan IPA untuk siswa kelas IV SD khususnya pada materi upaya pelestarian sumber daya alam.

\section{METODE}

Ditinjau dari tujuannya dalam mengembangkan produk, penelitian ini digolongkan sebagai penelitian dan pengembangan atau Research and Development $(R \& D)$. Untuk desain penelitian ini peneliti menggunakan langkah-langkah dari penelitian dan pengembangan Borg and Gall (dalam Sugiyono 2015: 409) yang dalam prosedur pengembangannya hanya sampai pada tahap revisi produk akhir, yakni: 1) Potensi dan masalah. 2) Pengumpulan data. 3) Desain produk. 4) Validasi desain. 5) Revisi desain produk. 6) Uji coba produk. 7) Revisi produk akhir.

Dalam penelitian dan pengembangan ini subjek penelitian berdasarkan penilaian para ahli yang terdiri dari 1 orang ahli media, 1 orang ahli materi, dan 1 orang ahli bahasa. Selanjutnya, uji coba produk secara perorangan (one to one) dengan melibatkan 3 orang siswa kelas IV di SDN 03 Lenteng Agung dan uji coba kelompok kecil (small groups) yang terdiri dari 7 orang siswa kelas IV di SDN 03 Lenteng Agung.

Instrument pengumpulan data dalam penelitian ini menggunakan kuesioner yang 
dijadikan pedoman untuk menilai produk yang akan dikembangkan. Kuesioner diberikan kepada siswa dalam tahapan uji coba, lalu kepada ahli media, ahli bahasa, dan ahli materi. Hasil dari validasi ini kemudian digunakan untuk menyempurnakan media yang akan dikembangkan sehingga layak digunakan dalam proses pembelajaran.

Teknik yang digunakan dalam penelitian pengembangan ini adalah statistik deskriptif. Menurut Sugiyono (2015: 333) statistik deskriptif adalah statistik yang digunakan untuk menganalisis data dengan cara mendeskripsikan atau menggambarkan data yang telah terkumpul sebagaimana adanya tanpa bermaksud membuat kesimpulan yang berlaku untuk umum atau generalisasi.

Data kualitatif berupa kritik dan saran yang dikemukakan oleh ahli media dan ahli materi serta siswa dikumpulkan untuk memperbaiki produk media interaktif powerpoint berbasis model discovery learning ini. Kemudian, data kuantitatif yang diperoleh dari kuisioner selanjutnya dikonversikan ke-data kualitatif dengan skala 5 (skala likert) untuk mengetahui kualitas produk dengan uraian berikut:

Tabel 1. Skala Likert

\begin{tabular}{|l|c|}
\hline \multicolumn{1}{|c|}{ Pilihan jawaban } & Nilai skala \\
\hline Kurang Baik (KB) & 1 \\
\hline Kurang (K) & 2 \\
\hline Cukup Baik (C) & 3 \\
\hline Baik (B) & 4 \\
\hline Sangat Baik (SB) & 5 \\
\hline
\end{tabular}

Konversi skala likert tersebut menggunakan acuan konversi pada Pendekatan Acuan Patokan (PAP) yang dikembangkan oleh Prof. Eko Putro Widoyoko dalam (Boga Metri Zain, dkk: 2020) seperti pada tabel dibawah ini:

Tabel 2. Konversi Nilai

\begin{tabular}{|c|c|c|c|}
\hline \multirow{2}{*}{$\begin{array}{c}\text { Data } \\
\text { Kuantitatif }\end{array}$} & \multicolumn{2}{|c|}{ Skor } & \multirow{2}{*}{ Kriteria } \\
\cline { 2 - 3 } & $X>X i+1,8 \mathrm{Sbi}$ & $\mathrm{X}>4,2$ & Sangat Baik \\
\hline 5 & $X i+0,6 \mathrm{Sbi}<X \leq X i+1,8 \mathrm{Sbi}$ & $3,4<\mathrm{X} \leq 4,2$ & Baik \\
\hline 4 & $X i-0,6 \mathrm{Sbi}<X \leq X i+0,6 \mathrm{Sbi}$ & $2,6<\mathrm{X} \leq 3,4$ & Cukup Baik \\
\hline 3 & $X i-1,8 \mathrm{Sbi}<X \leq X i-0,6 \mathrm{Sbi}$ & $1,8<\mathrm{X} \leq 2,6$ & Kurang \\
\hline 2 & $X \leq X i-1,8 \mathrm{Sbi}$ & $X \leq 1,8$ & Kurang Baik \\
\hline 1 & & & \\
\hline
\end{tabular}

\section{Keterangan :}

$\mathrm{Xi}($ Rerata skor ideal $)=1 / 2($ skor maksimal ideal + skor minimal idea

Sbi $($ Simpangan baku ideal $)=1 / 6$ (skor maksimal ideal - skor minimal ideal $)$

$\mathrm{X}=$ Skor empiris 


\section{HASIL DAN PEMBAHASAN}

Kegiatan penilaian media interaktif powerpoint diawali dengan uji validasi kepada para ahli yang terdiri dari ahli media, ahli bahasa, dan ahli materi dengan memberikan lembar validitas. Kemudian setelah memperoleh hasil penilaian dari para ahli peneliti melanjutkan uji coba ke siswa melalu tahap perorangan (one to one) dan tahap kelompok kecil (smalls group). Tabel 3 merupakan hasil penilaian kelayakan dari ahli media, ahli materi dan ahli bahasa

Tabel 3. Hasil Rekapitulasi Validasi Para Ahli

\begin{tabular}{|c|l|l|c|c|}
\hline No & \multicolumn{1}{|c|}{ Validator } & \multicolumn{1}{|c|}{ Aspek } & Skor & Ket \\
\hline 1 & Ahli media & $\begin{array}{l}\text { Aspek Tampilan } \\
\text { Aspek Pemograman } \\
\text { Aspek Efektivitas Media }\end{array}$ & 4,1 & B \\
\hline 2 & Ahli Materi & $\begin{array}{l}\text { Aspek Kebenaran Isi } \\
\text { Aspek Pembelajaran }\end{array}$ & 4,6 & SB \\
\hline 3 & Ahli Bahasa & $\begin{array}{l}\text { Aspek Kesesuaian } \\
\text { Penggunan Bahasa } \\
\text { Aspek Kesesuaian Kalimat }\end{array}$ & 4,8 & SB \\
\hline \multicolumn{2}{|c|}{ Rata-Rata } & 4,5 & SB \\
\hline
\end{tabular}

Media Powerpoint yang telah dikembangkan selanjutnya dinilai oleh para ahli. Ahli media memberikan skor 4,1 dengan kategori baik, artinya media tersebut layak untuk digunakan. Pada aspek tampilan media ini sangat menarik karena sudah dilengkapi penggunaan teks, gambar, animasi, audio, dan video yang sesuai dengan isi materi pembelajaran. Selain itu, tata letak tombol navigasi juga sudah ideal. Selanjutnya, pada aspek pemograman media ini sangat mudah untuk digunakan karena tombol navigasi jelas dan konsisten, pergantian antar slide cepat dan penggunaan elemen tombol sudah sudah sesuai dan bersifat interaktif. Aspek efektiviatas media menunjukkan bahwa media ini dapat menarik minat belajar, mningkatkan motivasi siswa dan rasa ingin tahu siswa sehingga dengan adanya media ini dapat memudahkan kegiatan belajar.

Hasil penelitian untuk ahli materi menunjukkan skor yang diperoleh adalah 4,6 dengan kategori sangat baik sehingga produk ini layak untuk digunakan. Hal ini karena media yang dikembangkan memiliki relevansi materi dengan kompetensi belajar, isi materi yang disajikan lengkap, jelas, sesuai dengan konsep keilmuan sehingga materi dalam media ini mudah untuk dipahami.

Penilaian oleh ahli bahasa diperoleh skor 4,8 dengan kategori sangat baik dan artinya media sudah layak untuk digunakan karena kalimat yang digunakan jelas, sesuai dengan kaidah PUEBI, dan penggunaan bahasa sudah sudah sesuai dengan karakter anak usia kelas IV SD. Berdasarkan penilaian ahli media, ahli materi, dan ahli bahasa maka diperolah ratarata skor 4,5 dengan kategori sangat baik sehingga dapat disimpulkan bahwa media powerpoint yang dikembangkan sudah layak digunakan dalam proses pembelajaran. 


\section{Hasil uji coba perorangan (one to one)}

Uji coba dilakukan dengan teknik stratified random sampling, yang terdiri dari siswa dengan kemampuan tinggi, kemampuan sedang, dan kemampuan rendah. Jumlah siswa sebanyak tiga orang, adapun hasil dari uji coba produk secara perorangan ditunjukan seperti pada tabel berikut:

Tabel 4. Hasil Uji Coba Perorangan (one to one)

\begin{tabular}{|c|c|c|c|c|}
\hline No. & Indikator Yang Dinilai & Skor & Rata-rata & Kategori \\
\hline 1 & $\begin{array}{l}\text { Petunjuk dalam media powerpoint } \\
\text { berbasis model discovery learning } \\
\text { ini jelas dan mudah dipahami }\end{array}$ & 13 & 4,3 & Sangat Baik \\
\hline 2 & $\begin{array}{l}\text { Tombol navigasi mudah untuk } \\
\text { digunakan }\end{array}$ & 13 & 4,3 & Sangat Baik \\
\hline 3 & $\begin{array}{l}\text { Tampilan media pembelajaran ini } \\
\text { menarik }\end{array}$ & 15 & 5 & Sangat Baik \\
\hline 4 & $\begin{array}{l}\text { Kombinasi warna pada tampilan } \\
\text { slide menarik }\end{array}$ & 14 & 4,7 & Sangat Baik \\
\hline 5 & $\begin{array}{l}\text { Tulisan dalam media ini dapat } \\
\text { dibaca dengan jelas }\end{array}$ & 15 & 5 & Sangat Baik \\
\hline 6 & $\begin{array}{l}\text { Gambar dan animasi jelas dan } \\
\text { menarik }\end{array}$ & 15 & 5 & Sangat Baik \\
\hline 7 & $\begin{array}{l}\text { Bahasa dalam } \\
\text { pembelajaran ini mudah dipahami }\end{array}$ & 15 & 5 & Sangat Baik \\
\hline 8 & $\begin{array}{l}\text { Musik pengiring tidak } \\
\text { mengganggu }\end{array}$ & 12 & 4 & Baik \\
\hline 9 & $\begin{array}{l}\text { Isi materi dalam media } \\
\text { pembelajaran ini jelas dan mudah } \\
\text { dimengerti }\end{array}$ & 14 & 4,7 & Sangat Baik \\
\hline 10 & $\begin{array}{l}\text { Soal dalam media pembelajaran } \\
\text { ini mudah untuk dipahami }\end{array}$ & 14 & 4,7 & Sangat Baik \\
\hline 11 & $\begin{array}{l}\text { Media pembelajaran ini membuat } \\
\text { saya lebih bersemangat dalam } \\
\text { belajar }\end{array}$ & 13 & 4,3 & Sangat Baik \\
\hline 12 & $\begin{array}{l}\text { Media ini membuat saya jadi lebih } \\
\text { termotivasi dalam mencari tahu }\end{array}$ & 12 & 4 & Baik \\
\hline 13 & $\begin{array}{l}\text { Media pembelajaran ini dapat } \\
\text { menambah pengetahuan saya }\end{array}$ & 14 & 4,7 & Sangat Baik \\
\hline 14 & $\begin{array}{l}\text { Media ini memudahkan saya } \\
\text { mempelajari mempelajari materi } \\
\text { IPA tentang upaya pelestarian } \\
\text { sumber daya alam }\end{array}$ & 13 & 4,3 & Sangat Baik \\
\hline 15 & Saya menjadi lebih aktif untuk & 12 & 4 & Baik \\
\hline
\end{tabular}




\begin{tabular}{|l|l|l|l|l|}
\hline $\begin{array}{l}\text { mencari solusi dalam proses } \\
\text { pembelajaran } \\
\text { menggunakan media ini }\end{array}$ & $\begin{array}{r} \\
\text { dengan }\end{array}$ & \\
\hline Jumlah & $\mathbf{2 0 4}$ & $\mathbf{1 3 , 6}$ & \\
\hline Rata-rata & \multicolumn{2}{|c|}{$\mathbf{4 , 5}$} & Sangat Baik \\
\hline
\end{tabular}

Hasil penilaian uji coba produk secara perorangan dengan melibatkan tiga siswa diperoleh nilai rata-rata sebesar 4,5. Berdasarkan tabel konversi nilai maka media interaktif powerpoint termasuk dalam kriteria sangat baik

\section{Hasil uji coba kelompok kecil (small group)}

Pada tahap ini peneliti melibatkan sebanyak tujuh siswa untuk mengetahui kelayakan media interaktif powerpoint dan hasil penilaian seperti pada tabel berikut:

Tabel 5. Hasil Uji Coba Kelompok Kecil

\begin{tabular}{|c|c|c|c|c|}
\hline No. & Indikator Yang Dinilai & Skor & Rata-rata & Kategori \\
\hline 1 & $\begin{array}{l}\text { Petunjuk dalam media powerpoint } \\
\text { berbasis model discovery learning } \\
\text { ini jelas dan mudah dipahami }\end{array}$ & 34 & 4,9 & Sangat Baik \\
\hline 2 & $\begin{array}{l}\text { Tombol navigasi mudah untuk } \\
\text { digunakan }\end{array}$ & 30 & 4,3 & Sangat Baik \\
\hline 3 & $\begin{array}{l}\text { Tampilan media pembelajaran ini } \\
\text { menarik }\end{array}$ & 33 & 4,7 & Sangat Baik \\
\hline 4 & $\begin{array}{l}\text { Kombinasi warna pada tampilan } \\
\text { slide menarik }\end{array}$ & 32 & 4,6 & Sangat Baik \\
\hline 5 & $\begin{array}{l}\text { Tulisan dalam media ini dapat } \\
\text { dibaca dengan jelas }\end{array}$ & 33 & 4,7 & Sangat Baik \\
\hline 6 & $\begin{array}{l}\text { Gambar dan animasi jelas dan } \\
\text { menarik }\end{array}$ & 33 & 4,7 & Sangat Baik \\
\hline 7 & $\begin{array}{lcc}\text { Bahasa dalam } & \text { media } \\
\text { pembelajaran ini mudah dipahami }\end{array}$ & 29 & 4,1 & Baik \\
\hline 8 & $\begin{array}{l}\text { Musik pengiring tidak } \\
\text { mengganggu }\end{array}$ & 28 & 4 & Baik \\
\hline 9 & $\begin{array}{l}\text { Isi materi dalam media } \\
\text { pembelajaran ini jelas dan mudah } \\
\text { dimengerti }\end{array}$ & 29 & 4,1 & Baik \\
\hline 10 & $\begin{array}{l}\text { Soal dalam media pembelajaran } \\
\text { ini mudah untuk dipahami }\end{array}$ & 33 & 4,7 & Sangat Baik \\
\hline 11 & $\begin{array}{l}\text { Media pembelajaran ini membuat } \\
\text { saya lebih bersemangat dalam } \\
\text { belajar }\end{array}$ & 34 & 4,9 & Sangat Baik \\
\hline 12 & Media ini membuat saya jadi lebih & 32 & 4,6 & Sangat Baik \\
\hline
\end{tabular}




\begin{tabular}{|l|l|c|c|c|}
\hline 13 & $\begin{array}{l}\text { termotivasi dalam mencari tahu } \\
\text { Media pembelajaran ini dapat } \\
\text { menambah pengetahuan saya }\end{array}$ & 30 & 4,3 & Sangat Baik \\
\hline 14 & $\begin{array}{l}\text { Media ini memudahkan saya } \\
\text { mempelajari mempelajari materi } \\
\text { IPA tentang upaya pelestarian } \\
\text { sumber daya alam }\end{array}$ & 34 & 4,9 & Sangat Baik \\
\hline 15 & $\begin{array}{l}\text { Saya menjadi lebih aktif untuk } \\
\text { mencari solusi dalam proses } \\
\text { pembelajaran dengan } \\
\text { menggunakan media ini }\end{array}$ & 34 & 4,9 & Sangat Baik \\
\hline Jumlah & $\mathbf{4 7 8}$ & $\mathbf{3 1 , 9}$ & $\mathbf{4 , 6}$ & Sangat Baik \\
\hline Rata-rata &
\end{tabular}

Jumlah skor penilaian berdasarkan uji coba kelompok kecil dengan 15 indikator adalah 478 sehinga rerata penilaian berdasarkan hasil uji coba adalah 4,6. Dengan mengacu pada tabel konversi nilai, maka media interaktif powerpoint menurut para siswa adalah sangat baik sehingga produk ini layak dipergunakan sebagai media pembelajaran untuk siswa kelas IV SD.

\section{PENUTUP}

Berdasarkan hasil validasi oleh para ahli dan hasil uji coba produk maka dapat disimpulkan bahwa media interaktif powerpoint dengan dikombinasikan model discovery learning menunjukkan layak untuk digunakan dalam proses pembalajaran. Akan tetapi, untuk mengetahui keefektifan produk ini maka perlu dilakukan uji coba lapangan (field test) yang juga maerupakan kelanjutan langkah pengembangan model Borg and Gall dengan sampel yang lebih luas sehingga dapat menyempurnakan tahap pengembangan media.

\section{UCAPAN TERIMA KASIH}

Terima kasih kepada pimpinan Fakultas Ilmu Pendidikan dan seruh dosen dan juga pimpinan SDN 03 Lenteng Agung dan juga Bapak/Ibu guru, yang dengan caranya masing-masing telah membantu penulis untuk menyelesaikan penelitian ini.

\section{DAFTAR PUSTAKA}

Astuti, Y. W., Hidayat, S., \& Auliandari, L. (2019). Development of Powerpoint with Discovery learning Environmental Pollution Material Class X SMAN 4 Palembang. 03(02), 57-65.

Arsyad, Azhar. Media Pembelajaran Edisi Revisi. Jakarta: PT Raja grafindo.2017

Azura, A. R., Kamariyah, N., \& Taufiq, M. (2019). Pengembangan Model Pembelajaran Discovery learning Terhadap Hasil Belajar Siswa Pada Mata Pelajaran Ipa Dengan Materi Perubahan Wujud Benda Kelas V Di Sd Al-. 171-180.

Daryanto.2016.Media Pembelajaran Peranannya Sangat Penting Dalam Mencapai Tujuan Pembelajaran. Yogyakarta : Gava Media 
Ernawati, R. Y. (2017). Pengaruh Penerapan Model Pembelajaran Discovery learning ,Media Pembelajaran Power Terhadap Muatan Ips. 11(1), 26-37.

I Made Putrayasa1, H. Syahruddin, I. G. M. (2014). Pengaruh Model Pembelajaran Discovery learning Dan Minat Belajar Terhadap Hasil Belajar Ipa Siswa. 2(1).Jalil, M. S. (2016). Pengembangan Model Pembelajaran Model Discovery learning Berbantuan Tips Powerpoint Interaktif Pada Materi Interaksi Makhluk Hidup Dengan Lingkungan, 6(2), 130-137.

Kristin, F. (2016). Jurnal Pendidikan Dasar PerKhasa Volume 2, Nomor 1, April 2016 Analisis Model Pembelajaran. 2

Kusrini, dkk. (2018). Efektivitas Model Pembelajaran Discovery learning Berbantuan Media Powerpoint Untuk Meningkatkan Hasil Belajar Siswa. MUSAMUS (Journal of Science Education), 1, 27-32.

Metri Zain, Boga. Wahidah, Baiq dan M.Ali, Nasaruddin. Pengembangan Media Pembelajaran Teks Anekdot Melalui ‘Whatsapp Dan Facebook’ Di Kelas X Smk Negeri 4 Mataram (Ke Arah Multimedia). Mataram. Jurnal Ilmiah Pendidikan Indonesia Volume 2 No. 1 Juni 2020

Muhammad Kadri, M. R. (2015). Pengaruh Model Pembelajaran Discovery learning Terhadap Hasil Belajar Siswa Pada Materi Pokok Suhu Dan Kalor Muhammad Kadri dan Meika Rahmawati. 1(1), 29-33.

Rahayu, A. (2018). Pengaruh Metode Mind Mapping Terhadap Motivasi Belajar Dan Kemampuan MengidentifikasiJenis Tanah. Artikel Skripsi Universitas Nusantara PGRI Kediri, 01(08), $1-13$.

Sugiyono. 2015. Metode Penlitian Kuantitatif, Kualitatif, dan R\&D. Bandung: Alfabeta

Suryani, Nunuk. 2010. Media Pembelajaran Inovatif dan Pengembangannya. Bandung :PT Remaja Rosdakarya

Yusfita Ernawa, Ria. 2017 Pengaruh Penerapan Model Pembelajaran Discovery learning , Media Pembelajaran Powerpoint Dan Prestasi Belajar. Malang: JPPI 